\title{
AIDS NA TERCEIRA IDADE: SENTIMENTOS, PERCEPÇÕES E PERSPECTIVAS DE MULHERES VIVENDO COM HIV/AIDS
}

\author{
AIDS in the Elderly: feelings, perceptions and perspectives of women \\ living with HIV/AIDS
}

Luna Pinheiro Celedônio ${ }^{1}$

Laurinete Sales de Andrade ${ }^{2}$

\begin{abstract}
Resumo
O presente artigo investiga os sentimentos, percepções, perspectivas de mulheres na terceira idade vivendo com HIV/AIDS e sua relação com o tratamento. A pesquisa foi realizada no Hospital São José de Doenças Infecciosas no Estado do Ceará. Foi utilizada uma metodologia qualitativa, sendo realizadas entrevistas semiestruturadas e a técnica de análise de conteúdo. Os resultados revelaram a vulnerabilidade feminina, com a presença da transmissão do vírus através dos maridos/companheiros e também em relacionamento novos e eventuais sem a cultura do uso do preservativo. Com relação à representação da AIDS, o confronto como a revelação do diagnóstico foram momentos de sofrimento, levando à tona sentimentos de medo da morte e do preconceito. No entanto, as entrevistadas que já vivem com o vírus há mais tempo, superaram essa etapa e tem novas perspectivas de vida, aderindo ao tratamento e refazendo suas vidas. Temos assim, a feminização da AIDS presente, o não uso do preservativo prevalente entre os idosos e o estigma ainda permeando os espaços. Com o avanço no tratamento, as perspectivas de vida ressurgem entre as pesquisadas. O estudo sinaliza a importância de evidenciar essa temática, promovendo ações prevenção para esse público e dando suporte ao viver com AIDS.
\end{abstract}

Palavras-chave: Terceira Idade. HIV/AIDS. Sexualidade. Subjetividade.

\begin{abstract}
This article investigates the feelings, perceptions, perspectives of women in the third age living with HIV/AIDS and their relationship with the treatment. The research was conducted at São José Hospital of Infectious Diseases in the State of Ceará (Brazil). It was used a qualitative methodology, being carried out semi-structured interviews and content analysis technique. The results revealed the female vulnerability, with the presence of the transmission of the virus from their husbands/partners and also in new and casual relationships without the habit of using condoms. The meaning of AIDS as a problem, in confrontation of the diagnosis were moments of suffering, leading to surface feelings of fear of death and prejudice. However, the interviewed who are already living with the virus for a longer period of time, surpassed this step and have new perspectives of life, adhering to treatment and recreating their lives. We have thus, this AIDS feminization, the non-use of condoms and stigma prevails among the elderly. With the treatment advances, the prospects of life improves between the researched people. It's important to highlight this subject, promoting preventive actions for this case of study and giving them support to live with AIDS.
\end{abstract}

Keywords: Third Age. HIV/AIDS. Sexuality. Subjectivity.

\footnotetext{
${ }^{1}$ Assistente Social da Residência Multiprofissional em Infectologia pela Escola de Saúde Pública-CE, Graduada em Serviço Social pela Faculdade Cearense. Telefone: 85 88869560. Email: lunnapinheiro@gmail.com.

${ }^{2}$ Mestre em Saúde Pública pela Universidade Estadual do Ceará (UECE), Preceptora da Residência

Multiprofissional em Infectologia da Escola de Saúde Pública-CE. Graduada em Serviço Social (UECE). Assistente Social do Estado do Ceará e da área da saúde da Prefeitura de Fortaleza, Ceará. E-mail: lauri1928@hotmail.com.

Serv. Soc. \& Saúde, Campinas, SP v. 13, n. 1 (17) p 47-60 jan./jun. 2014 ISSN 1676-6806
} 


\section{INTRODUÇÃO}

A Síndrome de Imunodeficiência Adquirida (AIDS) surgiu no início da década de 1980 no Brasil, em um momento, em que, no imaginário popular, as epidemias pareciam estar eliminadas. Ela apareceu como um problema grave e complexo, com ampla repercussão cultural e com inúmeras implicações no contexto das relações sociais.

A epidemia do Vírus da Imunodeficiência Humana (HIV), o agente causador da AIDS, surgiu com a ideia de que a doença está diretamente associada com a morte e a promiscuidade. Durante muito tempo, construiu-se a ideia de que para se adquirir o HIV era necessário fazer parte do "grupo de risco" que incluíam homens que fazem sexo com homens (HSH); usuários de drogas injetáveis (UDI) ou profissionais do sexo e hemofílicos. Foi então que, a partir dessa época, a infecção por HIV disseminou-se rapidamente pela população brasileira, e em pouco tempo, acometeu também homens com práticas heterossexuais, o que consequentemente, atingia mulheres e crianças (por transmissão materno-infantil).

Dados do Boletim Epidemiológico, com o ano base de 2011 do Ministério da Saúde, apontam que, desde a década de 1980 a junho de 2011, acumulam-se 608.230 casos de AIDS no país, sendo $65,4 \%$ no sexo masculino e $34,6 \%$ no sexo feminino. Estimavam cerca de 40 homens para cada mulher com AIDS no ano de 1983 e chegou a 1,7 homens a cada mulher no ano de 2011.

O envelhecimento da população é uma realidade da sociedade brasileira. $\mathrm{O}$ envelhecimento global causou um aumento nas demandas sociais e econômicas no mundo todo. O crescimento da população idosa no Brasil e no mundo é algo relevante nas pesquisas, e segundo dados do Instituto Brasileiro de Geografia e Estatística (IBGE), aponta-se que até o ano de 2025, o Brasil será o sexto país no mundo com o maior número de idosos, correspondendo a $15 \%$ da população brasileira. Um número que representa um crescimento três vezes maior que a idade adulta (BRASIL, 2006).

O aumento nos índices das pesquisas vem confirmando o vírus como uma ameaça à saúde pública e a tendência sugere que, em pouco tempo, o número de idosos contaminados pelo HIV será ampliado significativamente, principalmente, devido à vulnerabilidade física e psicológica, pouco acesso a serviços de saúde, além da invisibilidade com que é tratada sua exposição ao risco, seja por via sexual ou uso de drogas ilícitas. Além disso, a falta de campanhas destinadas aos idosos faz com que esta 
população esteja, geralmente, menos informada sobre o HIV e menos consciente de como se proteger (ARAÚJO; SALDANHA, 2006).

Outro fator que acaba contribuindo para esse grande índice é a sexualidade estereotipada que é produzida culturalmente na sociedade. Os estereótipos de que as pessoas idosas não têm interesse por sexo ou que são incapazes de sentir algum estímulo sexual, ainda é amplamente difundido. E, concomitante a isso, a prática sexual sem proteção contribui para que esse diagnóstico em pessoas idosas aumente cada vez mais. A possibilidade de uma pessoa idosa ser infectada pelo HIV parece ser invisível aos olhos da sociedade e dos próprios idosos, visto que a sexualidade, nesta faixa etária, ainda é tratada como tabu tanto pelos idosos quanto pela sociedade em geral (FONTES; SILVA, 2004).

O objetivo principal desta pesquisa é compreender as percepções e os sentimentos de mulheres que se encontram na terceira idade com o vírus HIV/AIDS, desvelando suas compreensões em relação ao seu diagnóstico, investigando como o reconhecimento da doença afetou seu cotidiano e suas relações sociais, como também, são as suas concepções de sexualidade pós-infecção e de preconceito e de estigma em relação ao HIV/AIDS.

\section{A AIDS na Terceira Idade}

A AIDS é uma doença que se manifesta após a infecção do organismo pelo HIV. Diferente do contexto do seu surgimento, atualmente, a AIDS compromete indivíduos de todas as faixas etárias. A ampliação dos números de idosos infectados com HIV pode estar relacionada a uma falha em relação às tentativas de prevenção para este grupo de idade, posto que, muitas vezes, as campanhas de prevenção concentrem sua atenção na população mais jovem. Outro fator que acaba contribuindo para esse grande índice é a sexualidade estereotipada, que é produzida culturalmente na sociedade. Os estereótipos de que as pessoas idosas não têm interesse por sexo ou que são incapazes de sentir algum estímulo sexual, ainda, é amplamente difundido. E concomitante a isso, a prática sexual sem proteção contribui para que esse diagnóstico em pessoas idosas aumente cada vez mais.

A possibilidade de uma pessoa idosa ser infectada pelo HIV parece ser invisível aos olhos da sociedade e dos próprios idosos, visto que a sexualidade, nesta faixa etária, 
ainda é tratada como tabu tanto pelos idosos quanto pela sociedade em geral (FONTES; SILVA, 2004).

O preconceito e o estigma aliado à falta de informação determinam algumas atitudes e propensões comportamentais que reforçam a vulnerabilidade do idoso para as Doenças Sexualmente Transmissíveis (DST), dentre elas, a AIDS. Os avanços tecnológicos na área da Medicina colaboraram para estender a longevidade, acarretando um aumento na expectativa de vida da população (LINSK apud FIGUEIREDO et al. 2000), porém, a possibilidade de uma pessoa idosa ser infectada pelo HIV parece ser remota aos olhos da sociedade. Segundo Leiberman (2000), as atitudes sociais sobre AIDS na velhice refletem concepções errôneas sobre o comportamento do idoso, pois o idoso é visto como um indivíduo que não possui interesses sexuais; que faz sexo apenas dentro do casamento e que não usa drogas (LEIBERMAN apud FIGUEIREDO et al. 2000).

Em suma, percebe-se que existe uma evolução no que diz respeito ao diagnóstico e tratamento do HIV/AIDS, porém, ainda existe uma imagem de que a população idosa está isenta de adquirir o vírus, por não ser compreendida dentro de um contexto de vulnerabilidade.

Vale salientar também a importância de debater a respeito da "feminização" da AIDS, que não se restringe apenas às mulheres jovens, mas abrange também mulheres na terceira idade. Atualmente, existe um aumento de casos de diagnóstico em mulheres com 50 anos ou mais. De acordo com o Núcleo de Prevenção da AIDS da Secretaria de Saúde, a feminização não é apenas uma realidade local, em todo o Brasil, existem índices semelhantes. E é dentro dessa realidade, que se contextualizará o debate da AIDS e a mulher na terceira idade.

\section{A Feminização da AIDS}

A epidemia da AIDS, em termos globais, se constituiu uma realidade para as mulheres desde o seu surgimento. O primeiro caso de infecção pelo HIV em mulheres foi datado no ano de 1981, nos Estados Unidos. Porém, a existência desses casos era compreendida como restritas às mulheres parceiras de usuários de drogas, de homens bissexuais, de hemofílicos ou de mulheres envolvidas na prática da prostituição. Foi somente na década de 1990 que surgiram as primeiras intervenções voltadas para esse segmento (BRASIL, 2007). 
De acordo com o Plano Integrado de Enfrentamento da Feminização da Epidemia de AIDS e outras DST's (2007), houve um aumento de 82\% no número de casos de AIDS registrados na população feminina entre 1995 (com 7.280 casos) e 2005 (13.279 casos).

Tendo em vista essa realidade, podem-se analisar algumas variáveis no que diz respeito à "feminização" do HIV. Levando em consideração esse quadro de disseminação do vírus entre as mulheres, pode-se destacar que há uma desigualdade de gênero aparente, quando se refere ao percurso histórico de desigualdades sociais, políticos e culturais, como também no que diz respeito às estratégias de prevenção e tratamento das mulheres infectadas (BRASIL, 2000).

No ponto de vista social, as mulheres ainda hoje carregam um tom de moralidade no que diz respeito aos seus comportamentos. Historicamente, há diferenças entre os papéis desempenhados por homens e mulheres, no seu acesso aos recursos produtivos e na sua autonomia para tomar decisões. Durante séculos, a cultura disseminada na sociedade é a de que a mulher tem que viver dentro dos padrões préestabelecidos, que ditam as regras dos seus comportamentos dentro e fora das suas relações sociais, tornando-a dependente do seu marido/companheiro em vários aspectos, principalmente em relação ao seu comportamento sexual. $\mathrm{O}$ acesso a bens materiais e simbólicos favorece aos homens, principalmente no que diz respeito aos métodos de prevenção. O controle exercido pela mulher no uso do preservativo masculino é mínimo, fazendo com que as mesmas dependam de acordos estabelecidos entre os seus parceiros, e tendo em vista que, na maioria dos casos de contaminação de mulheres pelo o HIV, o disseminador do vírus é seu companheiro, a mesma encontra-se, mais uma vez, vulnerável e exposta ao vírus (SALDANHA et. al., 2008).

Colaborando com esse raciocínio, Saldanha (2003) ainda menciona que as desigualdades de gênero exacerbam-se ainda mais nas mulheres das camadas mais pobres, pois, além das disparidades citadas acima, a estrutura social aparece como um fator determinante na constituição e na perpetuação de políticas de prevenção para essas classes. Pois, além do fenômeno da feminização do vírus, tem-se também a pauperização do mesmo, onde é crescente o número de portadores de ambos os sexos nas classes menos favorecidas.

Portanto, independente de faixa etária, raça ou profissão, as mulheres estão diretamente vulneráveis ao HIV, dentro desse contexto em que as relações de gênero e Serv. Soc. \& Saúde, Campinas, SP v. 13, n. 1 (17) p. 47-60 jan./jun. 2014 ISSN 1676-6806 
poder as tornam mais vulneráveis. E as mulheres na terceira idade merecem destaque, dada às circunstâncias acima citadas, pois demonstram uma percepção de risco baixa, não encarando a si mesmas como pessoas vulneráveis.

\section{Metodologia}

Para a realização da pesquisa, a escolha pela abordagem qualitativa foi a mais adequada, pois a finalidade da pesquisa é revelar significados e representações, tentando compreender reconstruções e comportamentos a partir de momentos vividos pelos sujeitos. Possibilitando uma compreensão dos processos subjetivos, através dos seus discursos, costumes etc. Minayo (1994) esclarece: "A abordagem qualitativa aprofundase no mundo dos significados, das ações e das relações humanas, um lado não perceptível e não captável em equações, médias e estatísticas [...]”. (MINAYO apud JÚNIOR, 2004).

Pesquisar as mulheres portadoras do HIV/AIDS na terceira idade requer uma abordagem interpretativa. Fez-se necessário compreendê-las, entender cada realidade, cada concepção e cada história particularmente. Nesse sentindo, procurou-se resgatar seus sentimentos e suas expectativas no sentido de conviver com o vírus da AIDS nessa faixa etária.

A pesquisa bibliográfica também foi primordial para a construção desse trabalho. Uma vez que fez necessário buscar um resgate histórico da gênese da saúde pública no Brasil, como também da descoberta do vírus HIV. Portanto, possibilitou um amplo alcance de informações, além de permitir a utilização de dados dispersos em inúmeras publicações, auxiliando na construção ou na melhor definição do quadro conceitual que envolve o objeto de estudo proposto.

Foram utilizados como instrumentos de pesquisa aqueles que facilitam as expressões do sujeito. A técnica utilizada para o desenvolvimento dessa pesquisa foi a entrevista semiestruturada. Para Minayo (1994), o que torna a entrevista um instrumento privilegiado de coleta de informações para as Ciências Sociais é a possibilidade da fala ser reveladora, de condições estruturais, de sistema de valores, normas e símbolos.

Assim, os depoimentos, em situação de entrevistas, foram a principal fonte de pesquisa, pois permitiu uma aproximação com o sujeito e uma aquisição de dados subjetivos. 
O estudo foi elaborado dentro de algumas etapas. Primeiro, a escolha dos sujeitos da pesquisa foi norteada, segundo um perfil já pré-estabelecido. Posteriormente foi organizada uma ficha de identificação dos sujeitos, juntamente com as perguntas que nortearam as entrevistas. O roteiro norteador da entrevista serviu de ponto de partida para que os sujeitos falassem livremente, sem preocupações e quando fosse necessário, ia-se aprofundando os pontos relevantes para a pesquisa. Serviu como um campo de expressão para os sujeitos participantes, estimulando a aparição de emoções e de reflexões sobre várias esferas diferentes.

As entrevistas tiveram a duração em torno de 20-30 minutos, todas foram gravadas e transcritas pela pesquisadora, juntamente com algumas anotações consideradas relevantes. Foram expostos os objetivos e finalidades do estudo e prestados todos os esclarecimentos.

O projeto foi submetido à avaliação e aprovado pelo Comitê de Ética em Pesquisa do Hospital São José de acordo com a resolução no ${ }^{\circ}$ 196/1996 (sob nº. 033/2004). Contemplando o direito de sigilo dos sujeitos da pesquisa, pois serão utilizados pseudônimos.

O estudo foi realizado no Hospital São José, referência em tratamento para doenças infecciosas, situado na cidade de Fortaleza do Estado do Ceará, e buscou-se fazer um recorte geracional e de gênero, buscando desvelar os impactos do diagnóstico de um vírus estigmatizado e carregado de preconceitos, em mulheres que se encontram na terceira idade.

\section{Resultados}

\subsection{Perfil dos sujeitos da pesquisa}

$\mathrm{Na}$ busca de compreender os significados, sentimentos e percepções que o diagnóstico do HIV ocasiona em seus portadores, os sujeitos escolhidos para pesquisa foram mulheres, com idade a partir dos 60 anos, usuárias do Hospital São José.

Tal recorte geracional e de gênero foi escolhido para esta pesquisa na tentativa de desvelar os seguintes aspectos: ser mulher, idosa e com diagnóstico de um vírus transmitido, na maioria dos casos, sexualmente. Dentro desse contexto, buscou-se compreender as diversas representações que tal diagnóstico acarreta na vida dessas mulheres. 
Foram entrevistadas seis mulheres diagnosticadas com o vírus, em internamento e tratamento ambulatorial no Hospital São José. Com idades entre 60 e 65 anos e com períodos do diagnóstico, variando entre 1 a 13 anos de convívio com a doença. Das seis, apenas uma é casada, duas são solteiras e três viúvas.

Foram abordadas as usuárias que já tinham o seu diagnóstico confirmado e que se enquadravam no perfil da pesquisa. Não houve nenhuma objeção incisiva para participar da pesquisa, apenas uma usuária teve um pouco de receio para aceitar, porém, depois de fornecer as devidas informações a respeito da pesquisa, a mesma concedeu seu depoimento.

\subsection{Análise das entrevistas}

A transformação dos dados coletados em resultados de pesquisa envolve a utilização de determinados procedimentos para sistematizar, categorizar e viabilizar a análise por parte do pesquisador. Dentre os mecanismos utilizados, a análise de conteúdo insere-se como uma proposta teórico-metodológica que colabora para essa transformação (CAPPELLE et al., 2003).

Para compreender, analisar e organizar os depoimentos, os dados obtidos foram distribuídos em categorias de análise a partir dos depoimentos das usuárias. Durante esse processo, despontaram quatro categorias: A chegada da AIDS e a vulnerabilidade feminina, as representações do HIV/AIDS, as mudanças de vida após a descoberta do diagnóstico e as perspectivas com a presença da doença.

As perguntas utilizadas na entrevista para nortear os depoimentos das usuárias foram formuladas com a finalidade de desvelar algumas percepções a respeito do HIV. Portanto, foram utilizadas quatro perguntas buscando compreender os sentimentos que perpassam ao falar sobre o diagnóstico; a maneira como o HIV chegou a suas vidas; as mudanças de vida em decorrência do diagnóstico e as suas perspectivas de vida.

\section{Chegada da AIDS: A vulnerabilidade feminina}

\section{A infecção através do parceiro ou companheiro}

Desde a sua gênese até os dias atuais a infecção pelo vírus do HIV/AIDS é caracterizada, principalmente, pelo contato sexual. A forma escolhida para abordar o assunto buscou compreender o contexto cultural de contaminação de mulheres pelo 
vírus, abordando aspectos como: o transmissor do vírus ser o marido/companheiro; a relação com eles depois do diagnóstico; a compreensão do diagnóstico e se em algum momento, imaginaram a possibilidade de contrair essa infecção.

Eu peguei a doença pelo meu marido. Eu sabia que ele tinha um tratamento, mas era tudo escondido, eu não sabia de nada... Era tudo no maior sigilo, tudo escondido. Eu só descobri o que ele tinha depois dele ter morrido. (Suj. 1, viúva, 60 anos)

O impacto do diagnóstico da infecção pelo HIV repercute significativamente nas suas relações e no seu cotidiano. Adquirir uma doença através das suas relações dentro de um matrimônio ou de uma relação com o seu atual companheiro, causou-lhes um desconsolo. Três entrevistadas souberam da existência da doença após o óbito dos seus maridos, que as expuseram a uma doença grave, tornando-as muito mais vulneráveis à contaminação.

\section{A presença de sexualidade após diagnóstico}

$\mathrm{O}$ ato de envelhecer não significa e nem deve ser associado à característica de um indivíduo assexuado. Apesar de ainda se ter uma construção social e cultural de que quando o indivíduo chega nesse determinado momento da vida, ele não exerce mais a prática sexual. Tal mito precisa ser desvelado para que esse público também seja encarado como indivíduos vulneráveis a adquirir qualquer infecção sexualmente transmissível quanto qualquer outra pessoa com idade inferior.

Alguns depoimentos permitiram perceber que as depoentes exerciam sua sexualidade como em qualquer outro momento de sua vida, sendo elas solteiras, divorciadas/separadas ou viúvas. O fato de estarem dentro da terceira idade não excluiu a prática sexual das mesmas, e isso pode ser considerado como o principal fator para que os índices de infecção pelo HIV em pessoas idosas cresçam a cada dia.

A gente se envolve com esses homens, quem disse que eles querem usar camisinha com a gente?! Querem não!! Diz que é muito ruim... Aí né... a gente acaba tendo uma relação desprotegida porque jamais imagina que a pessoa seja doente. Mas hoje me preservo e preservo o meu companheiro também. (Suj. 6, Solteira, 62 anos)

Nos últimos anos, aconteceram algumas mudanças na concepção e na prática da sexualidade na terceira idade. Existem alguns fatores que contribuíram para esse processo, como: as relações sexuais deixaram de ser apenas para procriar e tornaram-se fonte de satisfação e realização para todas as pessoas, de todas as faixas etárias; a Serv. Soc. \& Saúde, Campinas, SP v. 13, n. 1 (17) p. $47-60$ jan./jun. 2014 ISSN 1676-6806 
progressão de pessoas que chegam a essa faixa etária sem querer abrir mão da sua vida sexual; e com o surgimento da AIDS, de certa forma, houve uma obrigação em repensar a sexualidade, reforçando a necessidade de informação e de quebrar o tabu ao mencionar sua sexualidade (CASTRO, 2007).

\section{Representações sobre o HIV/AIDS}

\section{Os sentimentos e as percepções que deram significado ao diagnóstico}

Ser infectada pelo HIV/AIDS se tornou um acontecimento doloroso nas vidas das entrevistadas. A constatação do diagnóstico de uma doença associada à discriminação, ao preconceito e repleta de estigmas permite gerar novos comportamentos e sentimentos frente ao seu modo de viver, pois existe uma relação direta com a sua intimidade, com seus relacionamentos e com a morte. O HIV/AIDS quando adquirido assola o seu portador de dúvidas e incertezas. Não se sabe ao certo se irá desenvolvê-lo ou não ou como será o progresso do vírus.

Eu entrei em pânico. Eu não acreditava! Vivia para meu marido, para minha casa... Mas, pedi a Deus forças para enfrentar. Mas eu nunca tive problema com isso. Mesmo doente todo mundo me trata bem e ainda recebo telefonema das minhas amigas. Minha vida não mudou em nada. Nunca abri mão de nada... Continuo trabalhando, ainda não quero me aposentar e me apego a Deus e à minha família para seguir em frente. (Suj. 4, Viúva, 62 anos)

Quando se começa a fazer um resgate de como foram as reações ao saber do diagnóstico, muitas vezes, percebe-se uma descoberta traumática. Sente-se revolta, angústia, medo, dor, tristeza e traição. Depara-se com uma mistura de sentimentos ruins, principalmente, no medo da exposição e a aceitação de alguns familiares e amigos.

\section{O diagnóstico Oculto: A presença do medo e do preconceito}

A AIDS, desde o seu surgimento, é vinculada a grupos socialmente marginalizados, o chamado "grupo de risco". Tal concepção, como dito anteriormente, restringe o diagnóstico aos homossexuais, usuário de drogas injetáveis e profissionais do sexo. O fato de ser diagnosticado com o vírus estigmatizado e carregado de preconceito traz ao seu portador a sensação de desvio de conduta e o medo da exclusão social.

Eu procuro sempre força nos amigos que eu tenho na rede de apoio. E

é isso que me faz sair da tristeza e da depressão, porque eu não sou 
vista como uma coitada. Eu participo das reuniões, das conferências e dos movimentos que envolvem o HIV, e desse convívio, eu consegui fazer grandes amizades que me compreendem. (Suj. 2)

Mesmo depois de trinta anos do seu surgimento, ainda faz-se necessário disseminar informações a respeito do HIV, pois o preconceito existe quando não há conhecimento a respeito, ou seja, a falta de conhecimento a respeito do HIV faz com que pessoas sintam medo de contrair o vírus falando com um portador, sentando na mesma cadeira ou até dividindo alguns pertences.

\section{As perspectivas com a presença da doença}

\section{A presença da ideia de morte}

Na proporção que a epidemia do vírus HIV/AIDS vai tornando-se uma doença que entra na sua terceira década, o sentimento de morte que antes era tão imediato, atualmente, parece estar menos emergente. Porém, na década da sua eclosão, quando a infecção era totalmente desconhecida e não existia nenhuma forma de tratamento, os portadores do vírus não conseguiam resistir à doença.

Embora, atualmente, a associação HIV/AIDS x Morte tenha diminuído pois os tratamentos desenvolvidos são capazes de tornar a doença uma infecção controlável, as pessoas que se encontram na terceira idade hoje ainda têm na memória a imagem do HIV/AIDS como sendo uma doença devastadora como na sua gênese.

Em alguns depoimentos, consegue-se perceber que a notícia de imediato resgatou esse sentimento. Houve relatos de que ao receber o resultado positivo para o vírus, imediatamente o sentimento de morte foi associado.

A primeira coisa que eu pensei: minha vida acabou! Vou morrer e tudo vai acabar! Entrei em depressão, não queria sair de casa e fazer mais nada na minha vida... (choro) é uma notícia muito difícil de entender... (Suj. 6, Solteira, 62 anos)

\section{A superação do diagnóstico: A AIDS em sua vida}

Outra característica visível, nos depoimentos, é que essa sensação de morbidade desaparece no decorrer do tempo. Das seis entrevistadas apenas duas possuem um diagnóstico recente, as outras quatro já convivem com o vírus há mais de uma década, o 
que possibilita interpretar que o impacto do diagnóstico é comum para todas e que as perspectivas de vida de todas elas mudaram desde então.

Eu sou feliz, vou para praia... Faço tudo! Eu posso viver bem muito e tem gente que morreu primeiro que eu! Se eu me cuidar eu vivo muito tempo. (Suj. 5, Casada, 60 anos)

A construção cultural de que o HIV/AIDS deve ser diretamente ligado à morte vai se dissipando e abrindo espaço para que os portadores compreendam que, atualmente, o acesso universal aos medicamentos gratuitos garantidos pelo Estado aos usuários propicia uma redução significativa da mortalidade causada pela doença.

Portanto, há de se considerar relevante o aumento da sobrevida de quem convive com o HIV/AIDS, possibilitando que a parcela de idosos portadores do vírus progrida gradualmente.

\section{CONSIDERAÇÕES FINAIS}

Partindo do reconhecimento de que o envolvimento da população idosa na epidemia brasileira da AIDS tornou-se um objeto de pesquisa relevante na atualidade, o desenvolvimento desta pesquisa contribuiu para ampliar os conhecimentos a respeito de viver com HIV/AIDS na perspectiva de mulheres na terceira idade. Por tratar-se de um tema emergente, a literatura publicada a respeito dessa temática ainda é limitada, pois foi a partir das transformações no contexto histórico do vírus e o evidente fenômeno de feminização da infecção que estimulou alguns pesquisadores a estudarem o tema.

A terceira idade ocupa uma parcela importante no perfil epidemiológico da infecção do HIV/AIDS no Brasil, pois houve um aumento significativo de idosos portadores do vírus e um aumento ainda mais relevante no que se refere à feminização do diagnóstico. Pode-se perceber que o aumento desses índices foi em decorrência de alguns fatores importantes como: a vulnerabilidade feminina à infecção; a dificuldade de negociar o uso do preservativo nas relações; a carência de campanhas para essa faixa etária e a ideia de imunidade por viver um relacionamento estável corroboraram para acentuar a exposição dessas mulheres à infecção do HIV.

A repercussão a respeito da sexualidade na terceira idade ainda é repleta de preconceito. Percebe-se que ainda existe uma determinação social em relação à atividade sexual, como se a mesma se extinguisse com o decorrer dos anos, levando em consideração a idade cronológica do indivíduo. A sexualidade estereotipada, que é 
produzida culturalmente na sociedade, contribui para que o número de idosos infectados pelo vírus cresça cada dia mais.

As análises das entrevistas comprovaram que a sexualidade na terceira idade deve ser um fator ponderado em algumas instâncias, pois três entrevistadas adquiriram a doença através de relações sexuais com seus maridos e outras duas retomaram suas relações afetivas e tornaram-se suscetíveis ao risco de contaminação. Isso evidencia uma questão importante para se pensar em meios de prevenção específicos à terceira idade. Portanto, essa faixa etária deve ser considerada vulnerável ao risco de infecção do vírus, onde o controle e a prevenção devem estar articulados com as campanhas informativas e com a rede de atendimento, promovendo ações que informem, previnam e promovam a saúde na terceira idade e impulsionem um aprimoramento dos profissionais que demonstram despreparo ao lidar com o diagnóstico nessa faixa etária.

Portanto a pesquisa serviu para evidenciar que alguns aspectos que surgiram junto com a HIV/AIDS, na década de oitenta, ainda prevalecem nos dias atuais. O estigma, o preconceito, a recusa, o medo, a discriminação social, o despreparo dos profissionais ao lidar com o diagnóstico na terceira idade e a escassez de políticas públicas, ainda estão presentes na vida dessas entrevistadas e de tantas outras pessoas que são portadoras do vírus.

Faz-se necessário que haja mudanças nesses diversos aspectos citados acima, pois se trata de cidadãs e cidadãos de direitos, assim, as mulheres de terceira idade, formam um grupo vulnerável que exige políticas públicas específicas tanto em nível de prevenção à AIDS como de suporte na adesão ao tratamento e à vida.

\section{Referências Bibliográficas}

BRASIL, Ministério da Saúde. Coordenação de Vigilância em Saúde - Departamento de DST, AIDS e Hepatites Virais. Boletim Epidemiológico. Brasília, 2010.

BRASIL, Ministério da Saúde. Plano Integrado de Enfrentamento da Feminização da Epidemia de AIDS e outras DST. Brasília, 2007.

CASTRO, M. P. O viver com HIV/AIDS na perspectiva de pessoas idosas atendidas em ambulatório especializado da cidade de São Paulo. São Paulo, 2007.

CEARÁ. Ministério da Saúde. Secretária da Saúde. Boletim Epidemiológico AIDS/DST. Ceará, 2011. 
FIGUEIREDO, M. A. C, et. al. HIV/AIDS em pessoas idosas. Vulnerabilidade, convívio e enfrentamento. VII Congresso Virtual HIV/AIDS: O VIH/SIDA na criança e no Idoso, 2000. Disponível em:

http://www.aidscongress.net/Modules/WebC_AidsCongress/CommunicationHTML.asp $\underline{\mathrm{x}} \mathrm{Mid}=36 \& \mathrm{CommID}=322$ Acesso em: 03/10/2012.

FONTES, K. S., et al. Representações do HIV na Terceira idade e a vulnerabilidade

do Idoso. .VII Congresso Virtual SIDANet, 2007. Disponível em: http://www.aidscongress.net/Modules/WebC_AidsCongress/CommunicationHTML.asp $\underline{\mathrm{x}} \mathrm{Mid}=36 \& \mathrm{CommID}=324$ Acesso em: 09/10/2012.

HOSPITAL SÃO JOSÉ, Conheça nossa organização. Fortaleza, 2000/Folder.

IBGE. Pesquisa Nacional por Amostragem de Domicílio. PNAD, 2009.

MINAYO, M. C. DE S.; DESLANDES, S. F.; NETO, O. C.; GOMES, R. Pesquisa social: teoria, método e criatividade. Petrópolis, RJ: Vozes, 1994. Disponível em: http://www.webartigos.com/artigos/resumo-do-livro-pesquisa-social-teoria-metodo-ecriatividade/49268/\#ixzz1xhp4KYy5Acesso em 01/06/2012.

SALDANHA, A. A. W. et al., Representação do HIV na terceira idade e a vulnerabilidade no idoso. VII Congresso Virtual SIDANet, 2007. Disponível em:http://www.aidscongress.net/Modules/WebC AidsCongress/CommunicationHTML. aspx?Mid=36\&CommID=324 Acesso em 09/10/2012.

SALDANHA, A. A. W; ARAÚJO, F, L. A AIDS na Terceira Idade na perspectiva dos Idosos, Cuidadores e Profissionais de Saúde. João Pessoa, 2006. Disponível em: http://www.aidscongress.net/Modules/WebC_AidsCongress/CommunicationHTML.asp $\underline{\mathrm{x}} \mathrm{Mid}=36 \& \mathrm{CommID}=307$. Acesso em: 15/09/2012. 